\title{
Leaching kinetics of gold mine tailings: the removal of manganese and iron by sodium carbonate
}

\author{
Tebogo Mashifana*, and Nastassia Sithole \\ University of Johannesburg, Department of Chemical Engineering Technology, P.O. Box 17011, Doornfontein 2088, South Africa
}

\begin{abstract}
South Africa is a mineral-rich country with numerous metals and minerals such as gold, copper, and platinum group metals which are exploited to a significant extent. In this study the leaching of heavy metals from gold tailings was studied using sodium carbonate using gold tailings from Sibanye gold. The effect of the key leaching parameters were studied: solvent concentration, temperature, leaching time and the kinetic models were used. Leaching is a hydrometallurgical process where metals are extracted by chemical dissolution, leaving behind a residue of inert minerals originally present as well as insoluble decomposition products of the reacted mineral. The effect of concentration and temperature was tested and it was found that highest Fe extracted(39\%) was at $0.5 \mathrm{M}$ and for $\mathrm{Mn}(46.3 \%)$ was at $0.25 \mathrm{M}$, both at $25^{\circ} \mathrm{C}$. it was also found that an increase in metal extraction depends on leaching time. The data obtained was modelled to determine whether the kinetic model follows the chemical controlled process or controlled diffusion process and it was found that the controlled diffusion model best fits the kinetic model at all temperatures.
\end{abstract}

\section{Introduction}

When processing gold, the extraction is never $100 \%$. Mining generates large volumes of tailings, with consequent disposal and environmental problems [1].The unrecoverable and uneconomic metals are discharged as slurry to the tailings dams which result in vast volumes of waste material in a form of tailings [2]. Poor management of gold tailings results in the escape of seepage, adversely affecting soils and water quality and also result in acid mine drainage containing toxic elements such as arsenic, chromium, copper, manganese, nickel and lead, so it can be treated as hazardous waste [3]. Due to this, mine operations are forced to treat tailings after recovering precious metals from ores prior to disposal. The main impacts associated with storage of tailings are Soil and water pollution (including groundwater), Dam safety and stability, Air pollution by dust, Visual or aesthetic impact, and Reclamation and rehabilitation [4]. Since tailings are generally transported and disposed as an aqueous slurry, dissolved elements may be deposited in nearby soils or transferred to waters and finally to living beings. Toxicity depends on how the tailings are being managed, $\mathrm{pH}$, total acidity, and concentration of dissolved metals [5]. Ferric iron, when discharged to surface water, is hydrolysed to produce hydrated iron oxide and more acidity, as a result the $\mathrm{pH}$ of the water is lowered, making it corrosive and unable to support many forms of aquatic life [5]. Major heavy metals found in mine tailings include silicon (Si), iron $(\mathrm{Fe})$, manganese $(\mathrm{Mn})$, zinc $(\mathrm{Zn})$, and minor elements are nickel (Ni), cobalt, copper $(\mathrm{Cu})$, and chromium $(\mathrm{Cr})$, arsenic $(\mathrm{As})$, lead $(\mathrm{Pb})$. Leaching is a hydrometallurgical process where metals are extracted by chemical dissolution, leaving behind a residue of inert minerals originally present as well as insoluble decomposition products of the reacted mineral [6-7]. In the chemical processing industry, leaching is known as extraction. Leaching has a variety of commercial applications, including separation of metal from ore using acid, and sugar from beets using hot water. There are several method used for evaluation of dissolution kinetic of metal in a solution during leaching process. The shrinking core model is the one which is commonly frequently or mostly used. When using the shrinking core model there are certain conditions to be assumed [7]:

- $\quad$ During the leaching process, the temperature must remain constant

- $\quad$ Monosized spherical particle

- The particle shrinks uniformly

- No effect of other substances present in an ore

The following equations are used in the shrinking core model:

Chemical reaction controlled process:

$$
t / \tau=1-(1-X)^{1 / 3}
$$

Liquid film diffusion controlled process:

$$
t / \tau=1-(1-X)^{2 / 3}
$$

Product layer diffusion controlled process:

$$
t / \tau=1-(1-X)^{2 / 3}
$$

Mixed controlled process:

Corresponding author: tmashifana@uj.ac.za 


$$
t / \tau=\left[(1-2 X / 3)-(1-X)^{2 / 3}\right]+b\left[1-(1-X)^{1 / 3}\right]
$$

Where, $\quad X=$ fraction of reacted particles, $\tau=$ time for the complete conversion of a particle $\mathrm{b}=$ multiplying factor for chemical reaction

\section{Experimental}

The leaching test was performed in a thermostatic shaker, a $\mathrm{pH}$ meter was used to measure $\mathrm{pH}$ before and after the leaching process. To measure the amount of solution and reagents used for the experiment, pipettes and measuring cylinders were used. A vacuum pump was used to filter the solution from the solids and an oven for drying. To study the chemical composition, mineralogy of the gold tailings and the microscopic structure of the solids before and after treatment, X-ray Fluorescence (XRF), X-ray diffraction (XRD) and Scanning Electron Micrograph (SEM) were used respectively. A Marlven particle analyser was used to study the particle size distribution during the leaching process. The leaching process was performed using gold tailings obtained from Sibanye gold. Sodium carbonate was used as the leaching reagent. The gold tailings was dried in the oven for 24 hours at $50{ }^{\circ} \mathrm{C}$. The leaching solutions of concentration ranging from 0.5 to $1 \mathrm{M}$ were prepared. The solutions were added on the gold tailings at solid loading of $20 \%, 30 \%$ and $40 \%$. A temperature of $25{ }^{\circ} \mathrm{C}$ and $50{ }^{\circ} \mathrm{C}$ were investigated with a starring speed of $200 \mathrm{rpm}$. The interval of 2 hours for six hours was allowed for sampling and the remaining material was leached for 24 hours. The samples taken were filtered and air dried. The solid particles were analysed for chemical composition, mineralogy, and the micrograph of the structure. The effluent was analysed for iron (Fe) and manganese (Mn) using ICP.

\section{Results and discussion}

\subsection{Elemental compositions before leaching}

XRF results for major, minor and trace elements are presented in Table 1. Silicon dioxide $(71.84 \%)$ is the major element, followed by aluminum oxide $(8.78 \%)$ and iron oxide (7.69\%).Magnesium oxide, sulfur trioxide, potassium oxide occurs in less amount. Traces elements such as zinc, copper, chromium, nickel, and lead occurs in significant amount.

\subsection{Mineralogical analysis before leaching}

From Figure 1, it was found that the gold tailings comprises mostly of the following minerals: quartz ( $\mathrm{SiO} 2)$, iron aluminum silicide (Fe3Al2Si3), hematite (Fe2O3) and Iron Sulfide (FeS).

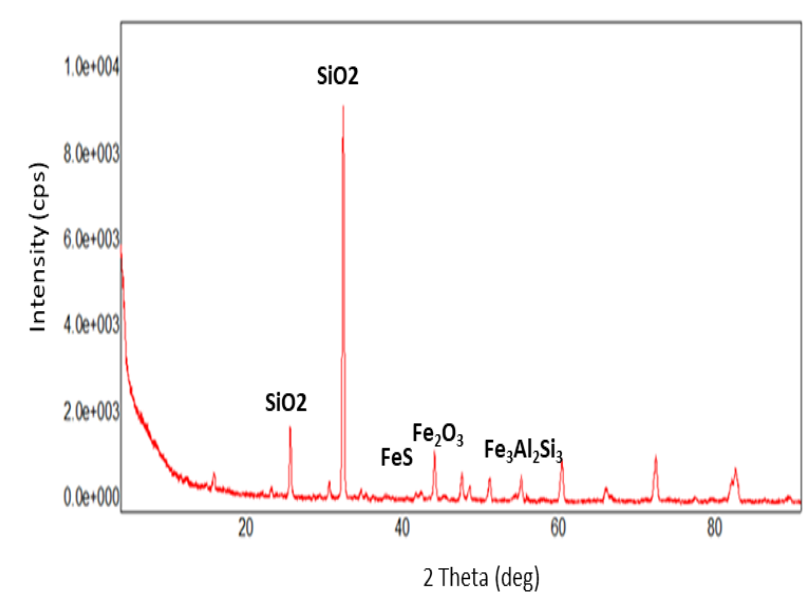

Fig. 1. XRD results of gold tailings before leaching.

Table 1. Elemental compositions of gold tailings.

\begin{tabular}{|l|l|}
\hline Components & Mass $\%$ \\
\hline $\mathrm{Na}_{2} \mathrm{O}$ & 0.1806 \\
\hline $\mathrm{MgO}$ & 4.5297 \\
\hline $\mathrm{Al}_{2} \mathrm{O}_{3}$ & 8.7896 \\
\hline $\mathrm{SiO}_{2}$ & 71.8444 \\
\hline $\mathrm{P}_{2} \mathrm{O}_{5}$ & 0.1105 \\
\hline $\mathrm{SO}_{3}$ & 3.4468 \\
\hline $\mathrm{Cl}_{2}$ & 0.1699 \\
\hline $\mathrm{K}_{2} \mathrm{O}$ & 1.5934 \\
\hline $\mathrm{CaO}$ & 0.7612 \\
\hline $\mathrm{TiO}_{2}$ & 0.4016 \\
\hline $\mathrm{Cr} \mathrm{O}_{3}$ & 0.1263 \\
\hline $\mathrm{MnO}$ & 0.0989 \\
\hline $\mathrm{Fe}{ }_{2} \mathrm{O}_{3}$ & 7.6945 \\
\hline $\mathrm{NiO}$ & 0.0983 \\
\hline $\mathrm{CuO}$ & 0.0120 \\
\hline $\mathrm{ZnO}$ & 0.0496 \\
\hline $\mathrm{Rb}{ }_{2} \mathrm{O}$ & 0.0062 \\
\hline $\mathrm{ZrO}$ & 0.0283 \\
\hline $\mathrm{PbO}$ & 0.0468 \\
\hline & \\
\hline
\end{tabular}

\subsection{Morphological analysis of gold tailings before leaching}

To study the morphology of the tailings, gold tailings were analysed using SEM and EDS. Table 2 below shows the elements present in tailings. It is evident that the tailings were predominated with $\mathrm{Si}, \mathrm{Al}, \mathrm{Fe}$ and $\mathrm{Mn}$. 


\begin{tabular}{||l||l|l|l|}
\hline Element & Weight\% & Atomic\% & Compd\% \\
\hline \hline Mg K & 3.33 & 2.91 & 5.52 \\
\hline \hline Al K & 5.07 & 3.99 & 9.58 \\
\hline Si K & 31.76 & 24.03 & 67.95 \\
\hline S K & 1.55 & 1.03 & 3.88 \\
\hline \hline Cl K & 0.23 & 0.14 & 0.00 \\
\hline \hline K K & 1.32 & 0.72 & 1.59 \\
\hline Ca K & 0.24 & 0.13 & 0.33 \\
\hline Ti K & 0.20 & 0.09 & 0.33 \\
\hline Fe K & 8.23 & 3.13 & 10.59 \\
\hline \hline O & 48.07 & 63.84 & \\
\hline \hline
\end{tabular}

Figure 2 shows the morphological image of gold tailings before leaching.



Fig. 2. SEM of gold tailings before leaching

The SEM image of gold tailings shows that the tailings consisted highly of silicon (greyish rock-like structure) which appeared as quartz in the gold tailings and $\mathrm{Fe}$ (black spaces in between the quartz) [1].

\subsection{The effect of sodium carbonate concentration on the leaching of $\mathrm{Fe}$ and $\mathrm{Mn}$}

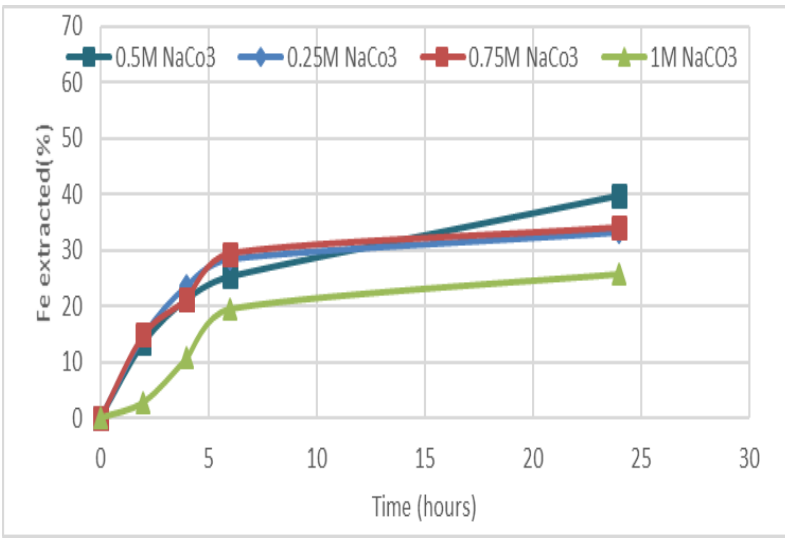

Fig. 3. Fe leached at varying reagent concentration and time.

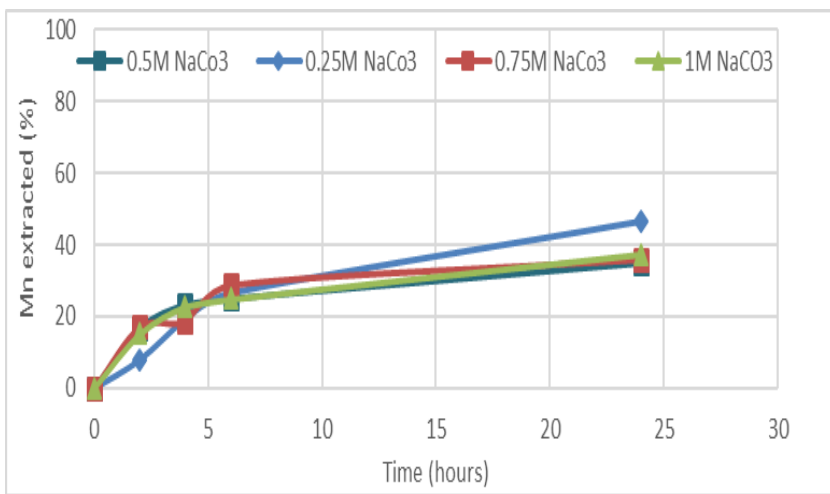

Fig. 4. Mn leached at varying reagent concentration and time.

The percentage of the heavy metals leached is dependent on the amount concentration used to leach the gold tailings. The general expectation was that an in increase in concentration will increase the amount of heavy metals leached. Figure 3 shows that the recovery of $\mathrm{Fe}$ increases with a decrease in reagent concentration; the highest attained Fe was (0.5 M -39\%), (0.25-33\%), (0.75-31\%) and $(1 \mathrm{M}-25 \%)$. The highest percentage of manganese extracted $(46.3 \%)$ was at a concentration of $0.25 \mathrm{M}$, Figure 4.

\subsection{The effect of Effect of temperature on the leaching of $\mathrm{Fe}$ and $\mathrm{Mn}$}

Temperature is an important parameter on the rate of extraction of metals. The effect of temperature was investigated by varying the temperature between $25^{\circ} \mathrm{C}$ and $50{ }^{\circ} \mathrm{C}$, while keeping concentration and speed constant.

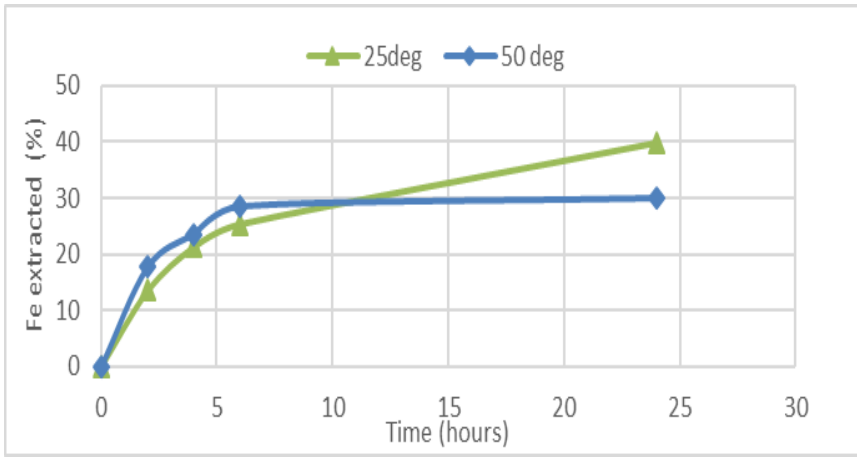

Fig. 5. Fe leached at varying temperature and time.

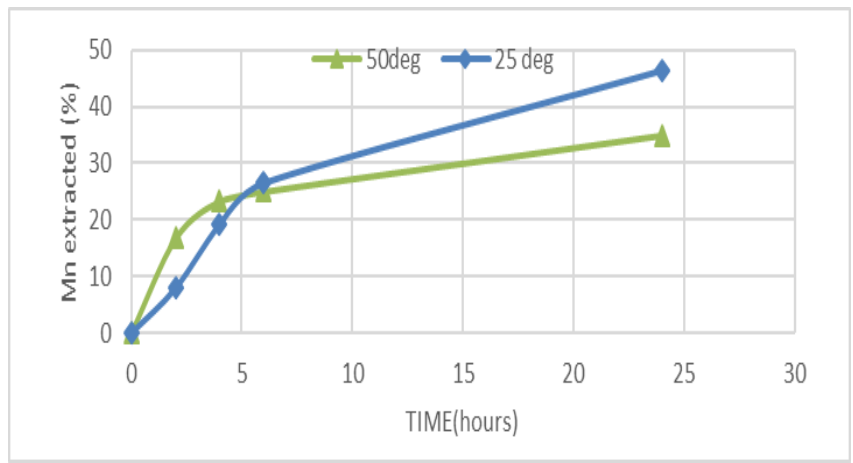

Fig. 6. Mn leached at varying temperature and time. 
Figure 5 and 6 shows the result for the effect of temperature on the leaching of gold mine tailings with the temperature kept constant at $25{ }^{\circ} \mathrm{C}$ and $50{ }^{\circ} \mathrm{C}$, the leaching speed at $200 \mathrm{rpm}$. Generally, an increase in temperature will increase the solubility of material to be extracted, but on this case the effect of temperature on leaching $\mathrm{Fe}$ and $\mathrm{Mn}$ from the gold tailings shows that at $25^{\circ} \mathrm{C}$ the amount of metals leached is higher than the one leached at $50{ }^{\circ} \mathrm{C}$. This can be attributed to the evaporation of sodium carbonate out the system which reduced the concentration of the solvent.

\subsection{Time dependence on leaching}

The effect of leaching time was investigated and varied from 2, 4, 6 and 24 hours. The leaching conditions were the concentration of $0.5 \mathrm{M}$ and temperature of $25^{\circ} \mathrm{C}$ for $\mathrm{Fe}$ and $0.25 \mathrm{M}$ at $25^{\circ} \mathrm{C}$ for $\mathrm{Mn}$. Results obtained on the influence of leaching time on recovery of $\mathrm{Fe}$ and $\mathrm{Mn}$ are presented in Figure 7.

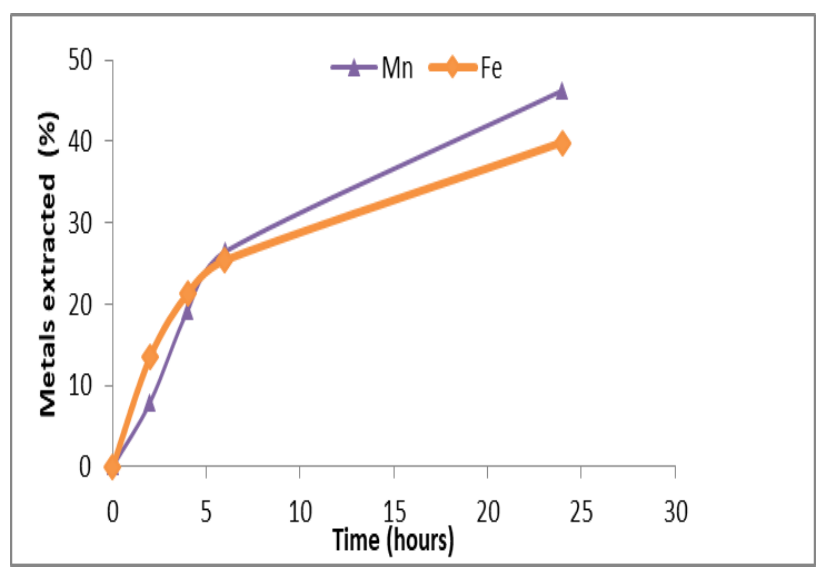

Fig. 7. Metal extraction as a function of leaching time at $25^{\circ} \mathrm{C}$ and $200 \mathrm{rpm}$.

The results show an initial fast rate as it approaches the maximum obtainable extraction rate. At 2 hours the amount extracted was $14 \% \mathrm{Fe}, 7.9 \% \mathrm{Mn}$. This increased to $39.8 \% \mathrm{Fe}$ and $46 \% \mathrm{Mn}$ after 24 hours. This depicts that the amount of metal extracted increased with leaching time. This can attribute to the fact that metals were not completely leached after 24 hours since not even $50 \%$ of the metals were leached.

\subsection{Kinetics analysis}

In this study the effect of temperature was used to determine the rate controlling. The data was analyzed using equations 1-4 which is represented by Figure 8 and 9 of shrinking core models for extraction of Fe from gold tailings. Figure 8 shows the plot describing the reaction controlled by a surface chemical reaction and Figure 9 shows the plot of equation describing the reaction controlled by diffusion through the surface layer. From the figures, it is evident that the best fit for extraction of $\mathrm{Fe}$ is at $25{ }^{\circ} \mathrm{C}$ and the control diffusion is the best compare to other kinetic models when looking at the $\mathrm{R}^{2}$.

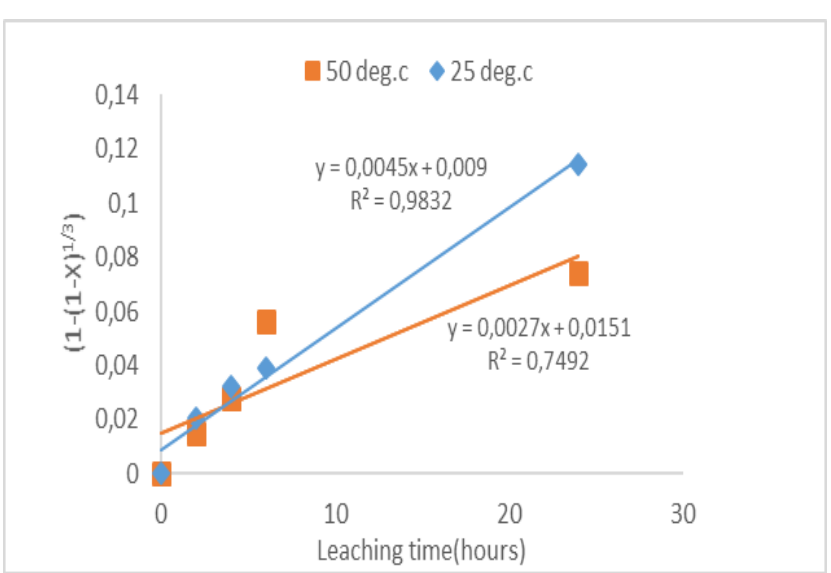

Fig. 8. $\left(1-(1-x)^{1 / 3}\right)$ against leaching time at different temperature.

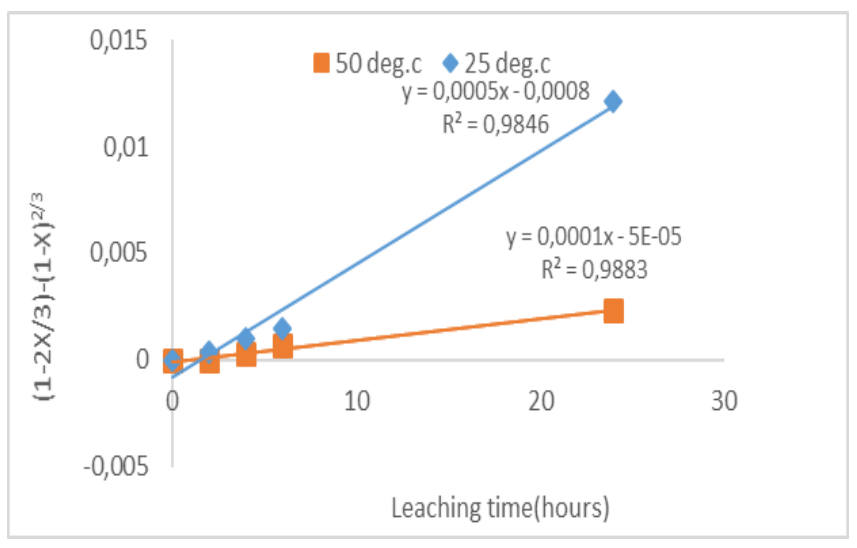

Fig. 9. $(1-2 x / 3)-(1-x)^{2 / 3}$ against leaching time at different temperature.

\section{Conclusion}

The leaching characteristics of $\mathrm{Fe}$ and $\mathrm{Mn}$ were investigated by looking at the influence of temperature, leaching reagent concentration and leaching time. From the results obtained it was concluded that the highest percentage of Fe recovered (39.8\%) was achieved with the concentration is $0.5 \mathrm{M}$ at the temperature of $25 \mathrm{oC}$ and the highest percentage of $\mathrm{Mn}$ recovered (46.3\%) was achieved with $0.25 \mathrm{M}$ at a temperature of $25 \mathrm{oC}$. It was found that diffusion control best fit all experimental data for each temperature and it was concluded that the rate of leaching depends on time.

\section{Acknowledgments}

The authors would like to thank the University of Johannesburg for providing resources to conduct the study.

\section{References}

1. T. Mashifana, N. Mavimbela, N. Sithole, Earth Environ Sci. 120, (2018).

2. J. Engels, Tailings Information., (2013). 
3. G.S. Simate, S. Ndlovu, J. Environ Chem Eng. 2, 3 (2014).

4. T. Rosner Univ of Pretoria (Doctoral dissertation), (1999).

5. M.W. Gitari, L.F. Petrik, O.Etchebers, D.L. Key, E. Iwuoha C. Okujeni 2006 J. Environ. Sci. Health. Part A, 41,8 (2006).

6. T. Moyo J. Petersen, J. S. Afri. Inst. Min. Met. 116, 6 (2016).

7. T. Mashifana, F. Ntuli, F. Okonta, S. Afr. J. Chem. Eng., 27, (2018). 